\section{Desde el fuera de órbita: acepciones de la modernidad indígena}

From out of orbit: meanings of indigenous modernity

\section{Saleta de Salvador-Agra \\ Yolanda Martínez-SuÁREZ ${ }^{\star \star}$}

\section{Resumen}

La globalización y su característica primordial, las TIC, encaran una renegociación de las tradicionales parejas dicotómicas de la lógica racional occidental. Si las tecnologías están asociadas a la modernidad, y los indígenas a la tradición, una reflexión en torno a las apropiaciones móviles, la versión puntera de las TIC, por parte de comunidades indígenas en contextos remotos como la Amazonía, se antoja

El artículo se enmarca en el proyecto "Ontología Móvil y Tecnociudadanía Nómade", financiado por la V Convocatoria Interna de Proyectos de la UTPL.

** Universidade de Vigo. Edificio de Facultades Campus de Ourense. 32004. Ourense. Correo electrónico: saletadesalvador@gmail.com e Institut de la Comunicació. Universitat Autònoma de Barcelona. Campus UAB - Edificio N, planta 1. E-08193. Bellaterra (Cerdanyola del Vallès). Barcelona. Correo electrónico: dalanyom@gmail.com especialmente interesante para debatir sobre tradición vs. modernidad, discusión en la que están muy presentes las brechas de primera y segunda generación, las asimetrías en la media literacy y la influencia de las variables de género, etnia y clase. Reflexionaremos apegadas a los resultados empíricos de un caso de estudio realizado, en Ecuador, en el marco del proyecto "Ontología móvil y tecno-ciudadanía nómade", cuyos resultados apuntan hacia una hibridación de las categorías de tradición y modernidad, materializadas en las apropiaciones tecnológicas por los indígenas shuar y kichwa Saraguro.

Palabras clave: media literacy, indígenas, apropiaciones tecnológicas, brechas, modernidad.

\section{Abstract}

Globalization and its primary feature, ICT, face a renegotiation of traditional dichotomous pairs of western rational logic. If technologies are associated with modernity, and indigenous with tradition, a reflection on mobile appropriations, the leading version of ICTs, by indigenous communities in remote environments such as the Amazon, seems particularly interesting to discuss on tradition vs. modernity. In this discussion there are a few topics very presents: first and second generation's digital divides, asymmetries in the media literacy and the influence of the variables of gender, ethnicity and class. We will reflect much attached to the empirical results of a case study in Ecuador, under the "Mobile Ontology and nomadic techno-citizenship" project, whose results point to a hybridization of the categories of tradition and modernity, embodied in technological 
appropriations by the Shuar and KichwaSaraguro indigenous.

Key words: media literacy, indigenous, technological appropriations, digital divide, modernity.

\section{Introducción}

Si los satélites de comunicaciones y las parabólicas supusieron el fin del harén musulmán en tanto revolucionaron las relaciones, según Fátima Mernissi (2005a, 2005b, 2006, 2007), situándonos en otro continente, el americano, los teléfonos móviles podrían ser la versión de las tecnologías que fulminasen la idea del "buen salvaje". Siguiendo con la analogía presentada por la escritora marroquí galardonada con el Premio Príncipe de Asturias, si los cielos de Rabal son un mar de antenas parabólicas, en la Amazonía ecuatoriana, el locus de ese skyline africano, lo ocuparían los dispositivos móviles digitales, la versión más puntera de las Tecnologías de la Información y la Comunicación (TIC). En el imaginario colectivo occidental, la representación de un indígena, de un hombre/ mujer de la selva, a priori, no porta tecnologías, y si lo hace éstas se observarían como una intrusión. Sin embargo, basta con entrar en una comunidad indígena, kichwa-Saraguro o shuar, en la mazonía ecuatoriana, para constatar que la realidad es otra.

La entrada por carretera a la Amazonía meridional, esto es, el camino que lleva a Zamora (la provincia más meridional de Ecuador) desde Loja (la provincia colindante por el Norte) anuncia lo que el visitante se encontrará al adentrarse en la selva. A saber: una vaya publicitaria de $4 \times 3$ metros muestra el siguiente eslogan en la entrada a la capital de provincia: "Claro te conecta" y justo debajo de la frase, el nombre del pueblo al que se entra, en este caso "Zamora", pero ocurre lo mismo en cada cabeza cantonal. Además de Claro (una de las dos compañías privadas de telefonía que operan en Ecuador), Movistar o CNT (las otras dos operadoras telefónicas con mercado en el país, la segunda de ellas de titularidad pública) también adornan con sus reclamos publicitarios -además del horizontecada pequeño bar, restaurante o tienda (farmacias incluidas, ya que en estos establecimientos también se pueden hacer recargas de las tarjetas telefónicas prepago). La modernidad de la selva colisiona con la esencialidad de una zona no contaminada, con la idea de la naturaleza "pura amazónica", también representada en otras carteleras publicitarias que conviven con las vayas de telefonía o las vayas de publicidad de la "Revolución Ciudadana", que señala los infocentros (centros gratuitos para la población equipados con ordenadores con conexión a Internet, telefonía fija, impresoras, televisores con DVD, etc.) promovidos por el gobierno de Rafael Correa. Desde su llegada al poder en 2007 , el equipo del mandatario ecuatoriano ha promovido una serie de cambios estructurales publicitados a través de campañas multimedias, donde se ha puesto un especial énfasis en las vayas publicitarias, en tanto soporte privilegiado para llegar a las clases populares. La cartelería insiste en los logros educativos, sanitarios o en las mejoras en infraestructuras del gobierno y se compone de grandes fotografías de ciudadanos en diversas ocupaciones, o paisajes donde la tradición y la modernidad conviven en supuesta harmonía, y eslóganes como "La Revolución Ciudadana Avanza" o el que da nombre a la campaña: "Avanzamos Patria".

En las pequeñas comunidades indígenas carentes, en su mayoría, de alcantarillado, 
con construcciones de madera, sin alumbrado público ni privado en ocasiones, proliferan los generadores eléctricos, los grandes televisores de pantalla plana de 40 pulgadas sobre las mesas de los restaurantes y las tiendas, los motores y las placas solares sobre los techos de paja o madera, las antenas de telefonía, los altavoces eléctricos en los centros sociales y edificios de encuentro que se emplean para convocar a los vecinos a las reuniones comunitarias, los micrófonos en los locales sociales, los sistemas de WiFi para conectarse desde lugares sin señal telefónica, las baterías de coche para cargar los equipos, las mesas de sonido y grandes altavoces en los lugares de uso comunitario, los infocentros o salas informáticas públicas, las antenas parabólicas para sintonizar canales de TV, las radios, las tabletas y sobre todo los teléfonos móviles.

En las canchas deportivas, donde se reúnen en el tiempo de ocio los vecinos residentes en las comunidades indígenas, la juventud se arremolina en torno a los teléfonos móviles, en los que se visualizan fotografías, se escucha (individualmente con audífonos o colectivamente con altavoces externos) y se comparte música (mediante bluetooth una vez descargada en zonas con cobertura telefónica), se envían mensajes, se socializan en las Redes Sociales Digitales (RSD), se proyectan vídeos, se toman fotografías, accionan la radio o la linterna, etc.

Una escena que, a priori, no convoca los imaginarios occidentales sobre la selva "virgen", "incorrupta", "paradisíaca", "inmutable" y "natural". Nuestra hipótesis es que la realidad, sin embargo, presenta un contexto cosmopolita donde se hibridan categorías y se difuminan las dicotomías de los binomios tradicionales. La modernidad tecnológica se presenta por tanto en un escenario donde sus propias particularidades harán emerger significados que, en última instancia, tal y como a continuación presentaremos, mostrarán una radiografía propia de una modernidad indígena. De tal manera que el objetivo que guiará este texto será estudiar las acepciones semánticas que adquiere la modernidad al ser deslocalizada, desplazada de su órbita.

\section{Metodología}

Los resultados aquí presentados derivan del proyecto "Ontología móvil y tecno-ciudadanía nómade. Caso de estudio las comunidades Shuar y Saraguro" financiado por la UTPL mediante su convocatoria de proyectos 2014. La investigación se realizó entre marzo y noviembre de 2014 y se desarrolló en la Amazonía oriental ecuatoriana, en concreto, en las provincias de Zamora Chinchipe y Morona Santiago.

La recogida de datos se hizo a partir de una triangulación metodológica, integrando técnicas cuantitativas (cuestionarios anónimos estructurados) y dinámicas cualitativas (realización de talleres, observación participante, entrevistas en profundidad, etc.). Dada la complejidad de la cuestión de estudio y la ausencia de aproximaciones teóricas previas, se ha optado por la combinación de métodos de investigación, con el objeto de abordar de la mejor manera el fenómeno que nos convoca. Si bien el proyecto de forma holística aplica técnicas de recogida de datos cuantitativas y cualitativas, aquí nos centraremos -de modo explícito- fundamentalmente en los datos obtenidos a partir de las entrevistas. Aunque conviene mencionar que la información recabada con otras técnicas sirve de base de 
elaboración de este texto. Las entrevistas se llevaron a cabo de dos maneras: virtualmente (en la primera fase del proyecto, entre marzo y junio de 2014, a través de Skype, a vecinos de las comunidades indígenas shuar de la provincia de Morona Santiago) y de manera presencial (en dos fases, entre marzo y junio y entre octubre y noviembre de 2014 en la provincia de ZamoraChinchipe a indígenas shuar y kichwa-saraguro).

Las personas entrevistadas se seleccionaron siguiendo criterios de diversidad con la finalidad de obtener lo más equilibrada posible (en cuanto a: sexo, edad, ocupación, zona de residencia) y también siguiendo criterios de oportunidad (cabe recordar que estamos ante un colectivo de difícil acceso (de Salvador y Martínez, 2015). De tal manera que la selección de los entrevistados presenciales se realizó a partir de los asistentes a los talleres impartidos en el marco del proyecto (ejecutados en las comunidades indígenas de Shaime, Tsarunts, Guayzimi, Zurmi, Nuevo Paraíso, Wants, San Carlos de las Minas y Achunts) y en los lugares donde se aplicaron las encuestas (en las comunidades de Tiukcha, Zhacay, San Vicente de Caney, Yacuambi, Zamora, Zumbi, La Paz y Guadalupe). Respecto a la selección de personas entrevistadas online, la selección respondió a la técnica de bola de nieve, esto es, a partir de un primer contacto, cada entrevistado nos fue facilitando otros posibles candidatos a colaborar con nuestra investigación, en función de las variables anteriormente mencionadas.

El resultado es una muestra total de 45 personas entrevistadas de etnia indígena responde a la diversidad que ofrece una pluralidad de situaciones, de voces y una amplia representación de maneras de ser shuar o de ser kichwaSaraguro en el presente (Ver Tabla1 y Tabla 2).
Tabla1. Datos de entrevistados shuar

\begin{tabular}{|l|l|l|}
\hline \multirow{2}{*}{ SEXO } & \multicolumn{1}{|c|}{ MUJERES } & \multicolumn{1}{c|}{ HOMBRES } \\
\cline { 2 - 3 } EDAD & \multicolumn{1}{|c|}{6} \\
\hline ESTUDIOS & $\begin{array}{l}\text { 15-65 años } \\
\text { primaria- } \\
\text { universitario }\end{array}$ & $\begin{array}{l}\text { 26-70 años } \\
\text { primaria- } \\
\text { secundaria }\end{array}$ \\
\hline & $\begin{array}{l}\text { Estudiante, } \\
\text { empleada hogar, } \\
\text { presidenta } \\
\text { comunidad, } \\
\text { agricultora, auxiliar } \\
\text { enfermería. }\end{array}$ & $\begin{array}{l}\text { Presidente } \\
\text { cantonal, } \\
\text { hostelero, } \\
\text { transportista, } \\
\text { artesano, } \\
\text { ganadero, } \\
\text { carpintero, } \\
\text { agricultor }\end{array}$ \\
\hline COMUNIDAD & $\begin{array}{l}\text { Zamora, Guayzimi, } \\
\text { Sumakyaku, San } \\
\text { Ramón, Yacuambi, } \\
\text { Saraguro. }\end{array}$ & $\begin{array}{l}\text { Zamora, } \\
\text { Guayzimi, Zurmi, } \\
\text { San Vicente de } \\
\text { Caney, Nuevo } \\
\text { Paraíso. }\end{array}$ \\
\hline
\end{tabular}

Fuente: Elaboración propia

Tabla2. Datos de entrevistados kichwa-Saraguro

\begin{tabular}{|l|l|l|}
\hline \multirow{2}{*}{ SEXO } & \multicolumn{1}{|c|}{ MUJERES } & \multicolumn{1}{|c|}{ HOMBRES } \\
\cline { 2 - 3 } & \multicolumn{1}{|c|}{17} \\
\hline EDAD & ES-50 años & 22-55 años \\
\hline OCUPACIÓN & $\begin{array}{l}\text { primaria- } \\
\text { universitario }\end{array}$ & $\begin{array}{l}\text { pocente } \\
\text { unimaria- } \\
\text { universitario }\end{array}$ \\
\hline & $\begin{array}{l}\text { vicepresidente } \\
\text { escuela, ex- } \\
\text { coordinadora } \\
\text { fundación, } \\
\text { investigadora, } \\
\text { presidenta } \\
\text { comunidad, } \\
\text { agricultora, } \\
\text { empleada hogar. }\end{array}$ & $\begin{array}{l}\text { Universitario, } \\
\text { comerciante, } \\
\text { funcionario } \\
\text { Ministerio, Síndico, } \\
\text { chófer, diseñador, } \\
\text { economista, } \\
\text { coreógrafo, } \\
\text { presidente } \\
\text { parroquial, } \\
\text { agricultor. }\end{array}$ \\
\hline
\end{tabular}




\begin{tabular}{|l|l|l|}
\hline COMUNIDAD & Nuevo Paraíso, & Nuevo Paraíso, \\
& Tsarunts, Taisha, & Pindal, Taisha, \\
& Gualaquiza, & Tiukcha, Sucúa, \\
& Tundayme, & Yantzatza, La \\
& Asunción, & Wants, Héroes del \\
& Muchime, & Cóndor. \\
& Yantzatza, & \\
& Nayanmak, & \\
& Conwima. & \\
\hline
\end{tabular}

Fuente: Elaboración propia

Las temáticas de las que se compone el guión de la entrevista en profundidad pueden enmarcarse en la siguiente categorización: acceso tecnológico y diferentes brechas (género, generacional, étnica, económica, educativa...), grado de implicación comunitaria/política, usos tecnológicos, tradición-modernidad tecnológica, historia comunicativa, socialización digital, etc. Los encuentros con las personas entrevistadas fueron grabados y se procedió a trabajar los datos a partir de las transcripciones íntegras o brutos de las entrevistas. Las categorías de análisis que se aplicaron a estas son fundamentalmente las temáticas antes descritas desglosadas ahora para facilitar el análisis de un material voluminoso. (Ver Tabla3).

Tabla 3. Categorías de análisis de las entrevistas

\begin{tabular}{|l|}
\hline CATEGORÍAS \\
\hline Necesidad de acceso \\
\hline Usos tecnológicos \\
\hline $\begin{array}{l}\text { Brechas de acceso } \\
\text {-étnica } \\
\text {-generacional } \\
\text {-de género } \\
\text {-idiomática }\end{array}$ \\
\hline
\end{tabular}

\begin{tabular}{|l|}
\hline Brecha de uso \\
-étnica \\
-generacional \\
-de género \\
-idiomática \\
\hline Tradición-modernidad \\
\hline Consciencia de la asimetría \\
\hline Apropiaciones \\
\hline Grado de implicación política \\
\hline Implicaciones tecnológicas comunitarias \\
\hline Socialización digital \\
\hline Actitud tecnológica \\
\hline
\end{tabular}

Fuente: Elaboración propia

En relación al idioma, todas fueron realizadas en español, sin intérpretes, ya que los propios entrevistados indígenas son conocedores del castellano. Si bien, el hecho de que no todos tengan el español como su lengua materna, se refleja en las estructuras gramaticales y sintácticas de muchos de sus enunciados, construidos mediante una traducción mental simultánea, y que hemos respetado en la transcripción de las entrevistas.

\section{Fuera de la órbita: la modernidad indígena amazónica}

La historia no tiene una dirección fija. Ya no se puede pensar la evolución en términos de una oposición entre la tradición y la modernidad, en la que esta última iría reemplazando poco a poco a la primera. Tradición y modernidad son un par de opuestos que han tenido una enorme aceptación, hasta el punto de que uno se ha identificado con la esencia misma del pensamiento y la acción hacia el progreso, y el otro con el inmovilismo que caracteriza a las culturas situadas fuera de la órbita de ese movimiento. La modernidad ha esencializado a la tradición hasta convertirla en un principio eterno, 
con el fin de situarse como su opuesto irreductible, ya que representa el cambio permanente. Ahora bien, la historia reciente nos enseña que la tradición no deja de reinventarse a través de insólitas apropiaciones de la modernidad que, por su parte, también se impregna de recomposiciones de un pasado al que desprecia. Y lo que con frecuencia pensamos que está esculpido en mármol de pasado es una tradición "reciente" (Bessis, 2008: 18).

Tal y como señala la cita inicial de la historiadora tunecina Sophie Bessis, la canonización de la pareja dicotómica, tradición-modernidad, ha teorizado como polos opuestos dos realidades que, a todas luces, lejos de su contraposición, nos emplazan a revisitar contextos donde el diálogo sobre el terreno hace surgir nuevos debates y apunta otros significados. En este sentido, la modernidad indígena amazónica sería, a día de hoy, un buen ejemplo de ello. Un contexto desde el que pensar la movilidad de una tradición que persigue y anhela situarse en una globalización que conlleva a una redefinición y creación de "identidades culturales nuevas" (Mernissi, 2006: 36).

Los reclamos, por parte de las comunidades indígenas estudiadas, de una identidad relacional, no estanca ni ajena a los ritmos frenéticos de unas tecnologías digitales que señalan las fronteras de la modernidad, nos permiten comprender sus necesidades identitarias. Esto es, cómo sery estar en el mundo actual es algo que, con claridad, se desprende de sus propios discursos, como a continuación veremos de la mano de sus reflexiones en primera persona, con las tecnologías como hilo conductor. Así, en primer lugar, podemos apreciar cómo los indígenas amazónicos son plenamente conscientes de la importancia del universo tecnológico en el mundo actual, del cual no quieren quedar al margen, insistiendo en que hay que "acoplarse" a los tiempos que corren. Afirmándose, de este modo, contra la tesis del inmovilismo anunciada por Bessis.
Cada vez somos más personas y necesitamos informarnos de las diferentes cosas que ocurren en el mundo, y de las nuevas tecnologías también, cada día tenemos que estar buscando información, actualizándonos en cuanto a un programa (Entrevistada kichwa 3, 18 años, Guayzimi).

Nosotros nos tenemos que acoplar, porque es bastante importante las tecnologías (...) Tenemos cómo comunicarnos, cómo estar al día en la comunicación (Entrevistada kichwa 9, 45 años, San Vicente de Caney).

Bueno, en la tecnología, nosotros como la etnia que pertenecemos, entonces más bien en ese tema nos facilita para que a nivel del mundo, nos conozcan, que también existimos esa etnia y que también estamos estudiando, ocupando lugares políticos, entonces nos van conociendo a través del Internet (Entrevistado shuar 6, 38 años, Nuevo Paraíso).

Bueno yo lo entiendo que la tecnología estamos viviendo en un mundo globalizado, entonces el pueblo shuar debe estar al tanto de lo que está pasando de lo que el mundo globalizado está viviendo actualmente. Entonces yo pienso que hemos simpatizado esta situación de estar al frente de lo que pasa en el mundo (Entrevistado shuar 17, 55 años, Pindal).

Su querer estar en el mundo actual, su lectura sobre el impacto de las tecnologías, no es primordialmente percibida con el temor de una pérdida identitaria sino incluso como una herramienta aliada ante una aculturación que, lejos de acentuarse con la llegada tecnológica, muestra nuevas posibilidades de resistencia. De ahí que perciban como una potencialidad, hija de la globalización, el intercambio mediático transfronterizo como válvula de salvaguarda cultural.

Es importante que se vaya manejando de acuerdo a la realidad nuestra y eso nos permite conjugar mejor nuestra realidad y tener ese espacio en conjunto, adaptando esa vida moderna con la tecnología (Entrevistado shuar 12, 35 años, Sucúa).

(La tecnología) ayuda mucho también a adaptarse un poco sin perder nuestra identidad (Entrevistado shuar 12, 35 años, Sucúa). 
(La tecnología) sirve muchísimo y es un cambio total, bastante, en la sociedad globalizada porque no decir que nosotros como shuar debemos estar ahí, no somos un mundo aparte, tenemos que adaptarnos sin perder nuestra identidad, es lo más importante. Todo es posible en este mundo globalizado, pero sin perder nuestra identidad (Entrevistado shuar 15, 33 años, Yantzatza).

\begin{abstract}
A través de la tecnología uno también se puede hacer contacto en otros países y ahí las necesidades que el pueblo shuar a veces requiere de esta situación ¿Por qué? Porque en otros países no saben lo que vivimos el pueblo shuar. No saben, entonces necesitamos el apoyo de otros países para que el pueblo shuar salga adelante por medio de esta tecnología del celular, yo pienso que es muy importante (Entrevistado shuar 17, 55 años, Pindal).

El mundo es individualista y muy competitivo, pero si mantienes esa parte de comunidad, de estar en contacto... utilizar la tecnología, creo que, es un paso muy importante que tenemos que saber aprovechar en el buen sentido (...) Una herramienta de que se puede lograr muchas cosas más que civilizarse (Entrevistada shuar 18, 35 años, Sucúa).
\end{abstract}

En este sentido, tal y como dejan ver sus palabras, ellos aprovechan las oportunidades que les brindan las distintas tecnologías ante las nuevas necesidades (desplazamientos y migraciones, exigencias de ubicuidad o de aceleración de los ritmos, etc.). Esta relación los sitúa, nuevamente, alejados de las posturas pasivas e inmóviles que se presuponen a las culturas "fuera de órbita" como las amazónicas.

(Auxiliar enfermería tiene teléfono móvil desde hace un año para comunicarse con sus 12 hijos que están fuera) Están buenazos (los celulares). En los ordenadores no puedo manejar, es un problema. Pero el celular, ese, sí le puedo manejar. Tengo que aplastar, tengo que buscar, quién es él, quién es ella, entonces ya busco y llamo (Entrevistada kichwa 10, 65 años, San Vicente de Caney).

Se puede enviar, hacer compras, otras cosas de otros países. Yo no puedo hacer eso, solo tengo que encargar, deme comprando tal cosa del otro país que tiene que venir. Le digo a una amiga que maneja y estamos funcionando con ella (Entrevistada kichwa 10, 65 años, San Vicente de Caney).
Ahí ya cargo mi otra agenda, ahí cargan los nombres. En el caso que tengo que salir para la parte fuera, donde hay cobertura, sí, ahí es indispensable que hay que llevar el celular (Entrevistado kichwa 13, 35 años, Nuevo Paraíso).

(Móviles) Son muy importantes. Ahora en la vida, que nosotros necesitamos hasta para estudiar, para comunicarnos, para todo necesitamos la tecnología (...) Nos da muchas facilidades como para investigar, o hacer cualquier trámite por las Redes Sociales (Entrevistada shuar 7, 29 años, Tsarunts).

Bueno es importante tener todo ese tipo de tecnología porque no puede comunicarse con otra gente solamente de aquí sino de todo el mundo. Tener una Tablet, por ejemplo, cuando uno está fuera de casa, es más fácil llevarla o una laptop pequeña, para poder hacer esos trabajos. Nosotros en casa todos tenemos un celular, una Tablet. Los niños también y mi esposo. Me parece muy importante, también podemos estar en contacto, podemos vernos y podemos saber qué es lo que está pasando al instante y estamos actualizados en las noticias y que queramos conocer (Entrevistada shuar 13, 45 años, Sevilla Don Bosco).

Es muy importante, si no hubiera la tecnología de comunicación, no sería posible estudiar por ejemplo, a distancia (Entrevistada shuar 13, 45 años, Sevilla Don Bosco).

En definitiva, los kichwa-Saraguro y los shuar amazónicos, conocedores de que las tecnologías digitales implican un cambio irrenunciable, ponen énfasis en las mejoras importadas, sobre todo en lo que respecta a su vida cotidiana actual donde los celulares "les organizan" el tiempo y el espacio.

Muy diferente todo era allá, por ejemplo, ahora mismo, en el momento de convocar, todo era que alguien tenía que dejar un oficio, alguien tenía que llegar allá. Ahora mismo, a veces, teníamos que enviar un oficio por la Cooperativa Zamora, por tal Cooperativa de transporte. Pero yo, ahora, simplemente redacto una convocatoria y envío directamente a otra persona, listo. $\mathrm{Y}$, a veces, solamente les pego un toque y reviso mi correo, que ya envié y ya está, listo (...) Se ahorra tiempo, dinero y hay mayor eficiencia (Entrevistado kichwa 1, 26 años, Guayzimi).

Nos hace ahorrar muchos viajes. A veces, solo lo podemos hacer a través de, comunicándonos por celular, de una llamada, o un mensaje, y no tenemos que estar 
perdiendo más tiempo, a lo mejor viajando a tal lugar. Nos ahorra viajes (Entrevistada kichwa 3, 18 años, Guayzimi).

Si nos cambia (las tecnologías), al menos, nos cambia en el sentido de que nos facilitan mejor. Si se pone uno una nota en la agenda que de pronto por otras actividades, estás imprevisto y pones una nota y te recuerda que es lo que tienes que cumplir, nos hace un poco que seamos más puntuales con respecto a las actividades que llevemos (Entrevistado kichwa 13, 35 años, Nuevo Paraíso).

La circunstancia de los celulares ha hecho que se puedan organizar mejor las cosas porque el mismo hecho de extenderlo, o generalmente nosotros utilizamos también como despertadores o como organizadores para el tiempo. Tenemos ya organizado el tiempo. Creo que eso es muy importante, porque a veces uno está distraído por ahí, el celular le puede ayudar a ver el tiempo (...) Ha habido muchos cambios, entonces, por ejemplo con los celulares uno también tiene, los jóvenes sobre todo, están al día. Por ejemplo, yo no sabía esto de Sonja, es un tipo de canción, mi hija escucha esto. Hay muchas cosas que están cambiando, y claro de nosotros como padres depende mucho para que otras culturas puedan asimilar la nuestra. Pero sí los jóvenes ya están con la moda al día o, a veces, dicen palabras en inglés que quizás los mayores no entienden, y así cosas están cambiando la cultura. Y si nosotros como padres le ponemos atención a eso, más adelante nuestros hijos ni siquiera van a conocer o conocerán a los shuar en los libros o algo (Entrevistada shuar 13, 45 años, Sevilla Don Bosco).

La teoría de Henry Jenkins de los "nativos digitales", y su interés natural por las tecnologías, cobra fuerza a nivel global al hilo de discursos tan equidistantes como el del propio académico estadounidense y sus seguidores centrados en Occidente, como el de Fátima Mernissi en su cruzada de desdicotomizar la democracia y el Islam desde el Norte de África, en Marruecos, o como el de los resultados de nuestro proyecto en la Amazonía ecuatoriana. En este último caso, los hallazgos apuntan a una brecha generacional compartida. En todos los discursos mencionados están presentes ambos polos, los que enfatizan la defensa de las tecnologías y aquellos otros más conservadores, ligados a las personas mayores en las diferentes culturas.
Fátima Mernissi destaca que, en Marruecos, la primera preocupación de la juventud es "la necesidad de obtener una formación adecuada en nuevas tecnologías, y sobre todo el deseo de aprender de modo autodidacta los idiomas extranjeros y los secretos del funcionamiento de un ordenador" (2005: 63). Esta tesis, que la socióloga marroquí extrae de la observación de las clases de la periferia de las grandes ciudades, así como de la población rural, es válida también para la población de la selva latinoamericana $\mathrm{y}$, concretamente, para los amazónicos ecuatorianos del sur en los que se centra nuestro estudio. Los indígenas de las etnias shuar y kichwa-Saraguro entrevistados manifiestan como prioritaria la necesidad de obtener un teléfono móvil, la versión más puntera de las TIC, así como otros dispositivos que les posibiliten estar conectados: tabletas, ordenadores con acceso a la Red, etc. y la necesaria educación digital que les permita poder aprovecharlos.

(En las TIC) estamos más inmersos los jóvenes. Bueno, yo sí me creo todavía joven, pero estamos más inmersos, los jóvenes, es por el mismo hecho de que nos estamos queriendo actualizar, estar a la moda, al tanto de todas las cosas que suceden, no solamente en el tema de las tecnologías, en ropa, en todo, entonces es por eso (Entrevistado kichwa 1, 26 años, Guayzimi).

Los jóvenes tienen más, porque a ellos les gusta la música, videos... música, Internet (Entrevistada kichwa 12, 32 años, Nuevo Paraíso).

Ahora todo el mundo tiene celular aunque sea el más baratito, el Nokia 1100 con linterna, pero todos tienen. Los jóvenes tienen un buen celular, un Smartphone no tan caro, pero tienen. Por lo general, los mayores, uno más tradicional para llamada o con música máximo. Un Nokia bastante simple sí lo tienen (Entrevistado shuar 10, 33 años, Sucúa)

Más se da en lo que es la edad de la juventud. Hasta 40 años, exagerando mucho, les gusta los teléfonos con bastante tecnología, que tengan un multiuso, que 
tengan todo lo que sea Redes Sociales. Pero, a partir de esa edad, la mayoría de las personas optan por tener un teléfono donde solo se puede contestar llamadas, llamar nada más (Entrevistada shuar 20, 25 años, Yantzatza).

El celular que tiene mi mamá no es el mismo celular que tengo yo. Mi mamá tiene un celular que solamente realiza llamadas, puede enviar mensajes de texto, cosas así. En cambio, yo tengo un celular que tiene acceso a Internet, donde yo puedo tomar fotografías, como te dije anteriormente, hacer muchas cosas más (Entrevistada shuar 21, 43 años, Nayanmak).

Mira, yo solo te pongo un ejemplo, yo tengo 3 hijos, tengo una hija que recién se acaba de graduar, tiene 17 años, mi hijo que tiene 15 años, yo te digo que ellos manejan al derecho y al revés lo que es el Internet, o arman o desarman una computadora, (Entrevistada shuar 21, 43 años, Nayanmak).

Como en otras culturas estudiadas, las resistencias a las $\mathrm{TIC}$ vienen de las generaciones mayores, mostrando por tanto una brecha generacional que podríamos pensar como transfronteriza, sin que por ello olvidemos las particularidades que presentan las condiciones locales. Aunque los mayores, según nos relatan los propios protagonistas, en algunos casos son recelosos y, en otros, muestran su apertura, sus dificultades de acceso tecnológico se presentan en sintonía con las teorías de Jenkins, anteriormente citadas.

(Los mayores) dicen que dañan a las personas (Entrevistada kichwa 2, 15 años, Guayzimi).

(Los mayores) lo ven mal. Ellos piensan que eso es algo malo, que no nos va a traer nada bien, nada bueno a nosotros, y piensan que es malo, ellos también no tienen conocimiento de lo que es eso, entonces, por eso creo que piensan eso (Entrevistada kichwa 3, 18 años, Guayzimi).

A los mayores no les gustan, dicen que las tecnologías son malas (Entrevistada kichwa 8, 16 años, Guayzimi).

Ellos (los mayores) toman de un lado negativo porque más antes ellos no lo utilizaban y hoy dicen que no, que eso no es bueno, a veces ellos están comunicando cosas que no les interesa. No dan fe, los mayores. La cosmovisión más antes no era esas cosas (Entrevistada kichwa 9, 45 años San Vicente de Caney).

Los ancianos de la comunidad están contentos le decía es algo novedoso para ellos, sobre todo cuando están pidiendo alguna opinión o cuenten alguna historia, o nos canten alguna canción, ellos pueden volver a escuchar todo eso, entonces, es novedoso para ellos y también porque muchos de ellos tienen celulares sus hijos, a veces les hacen hablar con parientes que están en otro lugar, ellos se sienten bien, están contentos con la aparición de los celulares" (Entrevistada shuar 13, 45 años, Sevilla Don Bosco).

Ellos (mayores) dicen que no les gusta (la tecnología) Porque no pueden manejar el teléfono. Tiene muchas tecnologías. Por eso dicen que no. Ellos quieren solo de esos antiguos (los de la linterna, Nokia 1100) (Entrevistada shuar 28, 29 años, Nuevo Paraíso).

Lo cierto es que la tecnología, a día de hoy, no es vivida como algo ajeno, perturbador o desestabilizador de sus propias formas de estar en el mundo sino como un elemento "integrado" o "apropiado" para su cotidianeidad y más desde la llegada de otra tecnología, que lleva años modificando su paisaje amazónico, a saber; las carreteras.

Fue un cambio bien rápido porque llegó la carretera, llegó la vía y todo cambió tanto que las casas shuar ya eran con ladrillo, con techos de Eternit, de zinc, con materiales tan extraños (...) Y habían alcantarillas. Ya no los chorros de las quebradas que uno se bañaba que jugaba (...) Pasó tan rápido. Tan rápido. Fue un cambio muy brusco por lo que ya entró la carretera y todo el material (...) Porque la carretera también ayuda muchísimo para el transporte. (...) Ahora todo el mundo tiene tecnología incluso llevan las refrigeradoras, llevan por canoa, por río, los tremendos televisores (de pantalla plana) que tienen (Entrevistada shuar 19, 46 años, Muchime).

Las carreteras facilitaron también el transporte de los vecinos de las comunidades hacia las ciudades con fines laborales o de estudio. Esta migración interna, aunque presenta serios retos de adaptación (pérdida de la socialización en sus idiomas ancestrales y conflictos en el retorno), se vive como una potencialidad, tal y como se puede apreciar en sus propios discursos: 
Porque aquí antes de que se hacía parroquia y antes de que llegara la carretera, casi no había muchos talleres. Ahora ya que se hizo parroquia llegó la carretera, ya está habiendo un poquito, entonces, la gente todavía no está muy bien informada (Entrevistada shuar 3, 18 años, Nuevo Paraíso).

Tenemos que seguir manteniendo la cultura. Pero al mismo tiempo tenemos la influencia de afuera que tienes que preparar más a tus hijos, que tienen que salir a preparase para que puedas tener mejores posibilidades de defender a tu cultura. Hay dos cosas que creo que hay que ir a la par (Entrevistada shuar 18, 35 años, Sucúa).

Los jóvenes ya que están en los colegios, universidades mismos, ellos ya pueden manejar, pueden escribir también en las computadoras (Entrevistada shuar 19, 46 años, Muchime).

Yo les decía, siempre, voy a estudiar. Pero voy a volver acá y voy a volver a enseñarles acá (Entrevistada shuar 19, 46 años, Muchime).

\section{Y, por supuesto, las nuevas vías que atraviesan la selva facultaron el acceso (conocimiento y compra) de las tecnologías digitales que se han introducido en la rutina diaria de las comunidades de la selva de manera privada, a la par que comenzaron a abrirse los mencionados infocentros públicos, dependientes del gobierno central. En sus descripciones podemos apreciar su situación concreta:}

Tenemos fijos y puntos de Internet. Hay un Internet que tiene un compañero de aquí, es privado, es de él, para dar servicio a la comunidad (Entrevistada kichwa 9, 45 años, San Vicente de Caney).

Aquí hay la bocina, el altoparlante, cualquier cosa, cualquier actividad que tienen que hacer en la comunidad entonces es por el altoparlante. El altoparlante ya lo prenden a cualquier hora. Todo rápido. Ya está dicho. Hay que reunirnos cuando llaman por el micrófono (Entrevistada kichwa 10, 65 años, San Vicente de Caney).

Ahoritas tenemos un altoparlante en sitio bien alto. Siempre para una sesión convocan por medio del altoparlante y ya está. Con celular tal vez algunas personas con los que están de acuerdo, pero no con todos, no hay cómo. Por ejemplo, aquí no tenemos cobertura, muy poca cobertura. Hay coberturas que tenemos que salir a diferentes partes para ponernos en contacto con otros lados (Entrevistado kichwa 11, 70 años, San Vicente de Caney).

Con la kipa, ellos le kipaban, le comunicaban a la comunidad. Yo los vi, porque en Saraguro siempre es el cacho que tocaban, ahoritas ya es el micrófono (para convocar a la comunidad) (Entrevistada kichwa 12, 32 años, Nuevo Paraíso).

Y, sobre todo, no hace mucho tiempo que esto del celular se dio ya a nivel nacional en nuestro Ecuador, solo en las partes capitales. Quito, Guayaquil manejaban el sistema. Pero a la parte de la provincia de Zamora se desconocía. Pero ahora, poco a poco, se está avanzando y nos facilita la comunicación. Al menos aquí todavía estamos aislados con la cobertura celular. Es algo complicado (la no cobertura). Al menos aquí teníamos telefonía comunitaria, un tiempo nos dio buen servicio, pero ahora está averiada. Lo han querido reparar la parte técnica, todavía no lo han logrado, dicen que son fallos del sistema de satélite. Pero en ello todavía nos facilita esto del Internet. Estamos utilizando vía Internet las comunicaciones, a través de chat, de correo, Facebook, eso... (Entrevistado kichwa 13, 35 años, Nuevo Paraíso).

Hace aproximadamente como unos siete años, que empezó la red de celulares, aquí en el Cantón, entonces, empezamos a utilizar dos o tres el celular (...) Empezamos con unos Nokia antiguos. Unos con linternita. Entonces, ahora ya tenemos unos táctiles con cámara, video y todo más avanzados (...) Y utilizamos en todo momento, porque el teléfono se ha hecho indispensable para la comunicación, en cualquier momento (Entrevistada shuar 7, 29 años, Tsarunts

Yo siempre digo que cada shuar tiene su teléfono celular aunque sea en Tiwintza, en Taisha pero salen, ponen su saldo, prenden su celular porque para nosotros era muy importante la comunicación, usted sabe nosotros nos comunicábamos mediante el tuntui -especie de tamborque era un instrumento musical, por medio de señales y también del cacho del toro y del caracol, también para comunicarnos esa señal que decíamos "Tuu Hai" que se escuchaba desde bastante lejos. Nos comunicábamos muchísimo, entonces, yo creo que al haber el celular, todos tienen, los jóvenes la mayoría tienen de esos carísimos, pero todos tenemos un celular (Entrevistada shuar 13, 45 años, Sevilla Don Bosco).

Sí, por ejemplo en Taisha y en Tiwintza son los lugares donde todavía no hay celulares móvil. Allí hay los infocentros que el gobierno ha implementado en toda las provincias, todos los cantones, incluso en las parroquias 
hay infocentros, en Taisha y en Tiwintza, la gente va a estos sitios para poder comunicarse y enviar información, a sus familiares, o a sus amigos (Entrevistada shuar 13, 45 años, Sevilla Don Bosco).

Yo he visto por ejemplo comunidades que prácticamente casi la mayoría de las personas tiene celulares (Entrevistado shuar 17, 55 años, Pindal).

Tú en Taisha (comunidad adentrada en la selva, de acceso aéreo o fluvial) vas a ver a jóvenes, a compañeros shuar, a gente mestiza, que tienen celulares, no tienen el teléfono convencional, tienen el celular y están escuchando música, están tomando fotos, cosas así (Entrevistada shuar 21, 43 años, Nayanmak).

El nexo entre el trabajo y las tecnologías, por una parte, y la conexión entre la educación y las tecnologías, por otra parte, dibujan una radiografía completa de las brechas de acceso y uso tecnológico, objeto de las reclamaciones de las comunidades indígenas kichwa-Saraguro y shuar amazónicas estudiadas. En cuanto al acceso, observamos que los propietarios de teléfonos móviles y de conexiones a Internet fijas o móviles, son fundamentalmente personas con empleos remunerados fuera de las comunidades indígenas, en tanto a mayores recursos mayor facilidad de acceso, lo que implica además de la brecha de clase, la mencionada brecha generacional y étnica, atravesadas por las desigualdades de género o "brechas digitales de género" tal y como se recogió en un estudio anterior: "Triplemente marcadas: desconexiones comunicativas en la Amazonía sur ecuatoriana" (Martínez, de Salvador y de Salvador, 2015). Allí se evidenció la interacción de las brechas de género, etnia y edad, y de manera transversal a las tres variables la clase-relación con la productividad, en el mismo contexto de estudio de este artículo. Dando como resultado la triple discriminación que sufren las mujeres mayores de etnia shuar frente a las kichwa-Saraguro y ambas frente a las mestizas. Un resultado acorde con la percepción de los propios protagonistas, quienes perciben las diferencias y la importancia de la cuestión económica.

Dentro de las comunidades, quien más usa es la persona que tiene ingresos económicos (Entrevistado shuar 2, 39 años, Sucúa).

Es un sistema que hay que tomar mucha precaución para poder dominar. Entonces, hay una diferencia, entre el sector mestizo, entre el sector Saraguro y la etnia shuar. Entonces siempre el sector shuar va quedando en el último lugar, mientras que el mestizo va en el primero, luego el Saraguro. Entonces solo los jóvenes pueden conectar Internet, celular... (Entrevistado shuar 6, 38 años, Nuevo Paraíso).

Se va comprando de acuerdo a los recursos. A veces se pierde, depende de la capacidad económica (Entrevistado shuar 10, 33, Sucúa).

No tengo celular. Sí tenía, lo que pasa es que estaba estudiando y por falta de recursos en mis graduaciones lo vendí y, desde ahí, ya no volví a comprar. Ahora a mi hijo le piden en el colegio entonces por darle a él, le di a él y mi esposo tiene (Entrevistada shuar 25, 32 años, Tsarunts).

En la misma línea, uno de los principales motivos apuntados por los indígenas entrevistados para comprarse un teléfono y adentrarse en el universo tecnológico es la necesidad de tener uno para poder desempeñar su trabajo, tal y como uno de ellos explica: "las tecnologías son muy buenas, porque sirven para comunicarse, no solo para comunicarse, sino, que es un elemento fundamental para el trabajo" (Entrevistada shuar 8, 27 años, Nuevo Paraíso).

A las mencionadas desigualdades en el acceso se le suman las brechas de uso, la necesidad de formación (en los diferentes niveles), de una educación mediática que ellos mismos reclaman y, con ella, la pretendida superación de la segunda brecha digital, o brecha de uso.

Entonces como nosotros ya tenemos acceso a la universidad, ya terminamos el colegio, que hay también 
algo nos capacitaron en la universidad, en este caso podemos ya manipular bien, la portátil, la computadora. Entonces, las personas que hablando de mis padres, ellos aún no lo pueden manipular bien (Entrevistado shuar 1, 22 años, Tsarunts).

Los indígenas son conscientes de la importancia de adquirir media literacy- en sintonía con las recomendaciones de UNESCO (2013)- y así lo manifiestan, apuntando directamente a los responsables de las dificultades que atraviesan a este respecto.

Es responsabilidad del gobierno el tema al respecto de capacitar a las personas que tienen que estar al frente, así mismo, capacitar a las personas de acá abajo del pueblo (Entrevistado kichwa 1, 26 años, Guayzimi).

Nos falta conocer, nos falta capacitarnos, nos falta, sobre todo, la parte de conocer, capacitarnos, operativizar el tema de y para esa operativización. Parece que nos falta herramientas (Entrevistado kichwa 1, 26 años, Guayzimi).

Hoy en día si no podemos manejar la tecnologías somos los analfabetos (Entrevistada kichwa 9, 45 años, San Vicente de Caney).

Todos tienen celular. Algunos que están muy viejitos, analfabetitos ellos no pueden utilizar, ellos no tienen. $O$ algunos que pasan solo en la finca, solo en las vacas, no tienen, para qué necesitan. Los hijos tienen, pero ellos no tienen (Entrevistada kichwa 10, 65 años, San Vicente de Caney).

Solo llamadas. Mensajes no, porque él (su esposo) casi no entiende mucho, porque no es de primaria, solo ha pasado a tercer grado. Por eso no mucho. Solo escribe, de repente. Fotos, música, sí, eso es un poco más fácil. Aquí sólo música. Cuando sale a Guayzimi, a Sararugo, Loja ahí sí puede usar (porque hay cobertura) (Entrevistada kichwa 12, 32 años, Nuevo Paraíso).

Necesitaríamos más talleres (de capacitación de tecnologías) (Entrevistado kichwa 13, 35 años, Nuevo Paraíso).

Aquí nos falta el manejo de las computaciones y tener más incremento de las computaciones o, como decir, la escuela de computación, computación del Internet, todo eso, para que las escuelas vayan practicando, los niños en cada establecimiento de la educación (Entrevistado shuar 4, 42 años, Yayu).
Hay bastante diferencia porque ya tienen mayor conocimiento en la tecnología. Los que no tienen celular todavía no saben cómo manejar un equipo. Si hay bastante diferencia, especialmente en mi pueblo. Estamos en ese proceso por eso nosotros como Fundación estamos tratando de que nuestra gente que conozca ese tema, que conozca algunos temas, hablando de la UNASUR, de la Cancillería, es importante porque mi pueblo no está capacitado en ese tema. Entonces nosotros con la tabla de involucrados nos ha ayudado porque es la ayuda en conocimientos, de capacitación, brindar a la gente. Estamos trabajando en ese tema (Entrevistado shuar 15, 33 años, Yantzatza).

Paralelamente a las reclamaciones de capacitación, los miembros de las comunidades indígenas emiten sus críticas constructivas ante la dificultad de acceso a las tecnologías. Situación que les provoca sentimientos de frustración e indefensión, así como de saberse víctimas de una injusticia social.

Es algo muy feo, porque te sientes incomunicado, no puedes comunicarte, si es que te vas de viaje, no puedes comunicarte con tu familia no. Es algo bien horrible (Entrevistada kichwa 3, 18 años, Guayzimi).

No tengo yo, pero veo. Me emociona, es ver rapidito para poder comunicar cualquier cosa de un lado a otro, malo o bueno, o lo que sea, pero está excelente. Yo sí veo que es importante. Para una enfermedad, de eso, se salva rapidito porque las comunicaciones largas llega (Entrevistada kickwa 7, 57 años, Guayzimi).

Mi sueño es comprar un teléfono fijo porque fijo si coge (cobertura), en un ladito también. (El móvil) se asienta ahí y no hay como hablar, moviéndome al ladito no hay como. Aquí fijo, mejor. De aquí al centro se puede llamar (Entrevistada kichwa 10, 65 años, San Vicente de Caney).

Muchas veces (siento frustración por no poder llamar). Casos que se han dado de super urgencias, urgencias en calamidad doméstica, la salud. A veces hemos intentando comunicar para pedir una ambulancia y no ha habido ni la posibilidad ni a través de Internet. No están conectados. Lamentable. Si tuviéramos una apertura de celular llamaríamos en cualquier momento que se necesitara (Entrevistado kichwa 13, 35 años, Nuevo Paraíso).

Como yo, a veces, estoy aquí haciendo un trabajo, a veces, conectado, a veces, bum, se va la luz, o, a veces, comienza a llover mucho porque eso está abajo en el 
CNT. Usted sabe que, comienza a interrumpirse las líneas. Entonces, ahí, sí, a veces, en el teléfono mismo, a veces, se va la luz, pero si tengo el celular donde hay cobertura llamo rápidamente y entonces, pero, a veces, aquí como estamos a la distancia, sí me he sentido discriminado. A veces, no sé cómo estarán mis hijos abajo. Yo sé que mis hijos tienen celular, pero si están en la parte de cobertura, rápido llamar. Pero no sé ellos cómo estarán. Sí, me he sentido discriminado por falta de comunicación (Entrevistado shuar 6, 38 años, Nuevo Paraíso).

Unos tuvieron teléfonos celulares y yo no tuve. $Y$, al sentir, cuando otros tenían y yo no tuve como comunicarme y yo tenía solo en el teléfono números en la agenda y me sentía, algo así, que yo no era nada, que yo no era nada importante (Entrevistado shuar 9, 26 años, Tiukcha).

Hubo un tiempo que sí sufrí bastante, por no tener un celular propio. Eso fue la gran ausencia y desde que tuve celular, realmente me ha cambiado mucho en cuanto a comunicación. Sin celular yo me siento nada, así desaparecido, y cuando utilizo otro dispositivo, o prestado, a veces uno no se siente dueño de esa máquina y siempre tiene la tensión de que se te puede dañar o que puedes causar alguna falla de la máquina ajena, etc. Entonces, he tratado de conseguir un buen celular y que tenga la posibilidad de darme mejor satisfacción que yo necesito (...) Como lo digo, en la Amazonía todavía se sufre a que haya buenas señales telefónicas. Entonces, casi siempre yo me olvido, trato de olvidarme de todo esto cuando voy a lugares donde no hay señal, simplemente es divertirme con la música, haciendo fotografías, poniéndome a jugar en el dispositivo. A veces, lo dejo prestado ahí y yo solamente me voy de viaje una semana, pero sí regreso así sufriendo con esas ganas de conocer qué ha pasado en mi ausencia, realmente es como que ha dormido una semana y ese impacto social, digamos, tecnológica, que a uno le converge, diríamos, a estar conectado a estos medios (Entrevistado shuar 11, 28 años, Bambantza).

Por ejemplo, yo me sé ir a Alto Nangaritza, allí no hay cobertura. Para mí es como estar refundido fuera de mi país. Y no puedo comunicarme y es difícil la comunicación. Y sí me siento un poco, me siento triste porque no sé cómo está mi familia, cómo están mis hermanos, mis familiares, mis amistades, qué está pasando, o sea totalmente me desconecto del mundo globalizado y no sé vivir (Entrevistado shuar 15, 33 años, Yantzatza).

Yo, personalmente, créemelo que uno se siente sin valor sin energía, porque uno a veces no tiene cobertura. A veces estás sin recarga, se puede decir, entonces eso es un poco... (discriminado) (Entrevistado shuar 17, 55 años, Pindal).
Sus reclamos, de acceso y uso, dibujan acepciones de la modernidad tecnológica que se ven reforzadas por las "insólitas apropiaciones" -recordando el texto con el que abríamos este apartado- a las que se ven constreñidos para no perder el ritmo de una modernidad de la que no quieren desembarcarse, a pesar de que está los sitúe "fuera de órbita". A partir de sus estrategias, diseñadas y marcadas por el contexto geopolítico en el que viven, podremos apreciar las asimetrías que asoman en su diálogo con la actualidad.

\section{De las "insólitas apropiaciones" indígenas: de justicia y asimetrías}

Si las tecnologías digitales surgen fuera de nuestro contexto de estudio, el hecho de hacerlas propias, ha llevado a estas comunidades indígenas a su apropiación, en el sentido otorgado por Thompson (1998), a este concepto. Sentido retomado de Martín Barbero (1987) y García Canclini (1995), y herederos del cuadro de Bonfill Batalla (1983). Así, para Thompsom la apropiación mediática consiste en lo siguiente:

\footnotetext{
Utilizaré el término «apropiación» para referirme a este proceso de comprensión y autocomprensión. Apropiarse de un mensaje consiste en tomar su contenido significativo y hacerlo propio. Consiste en asimilar el mensaje e incorporarlo a la propia vida, un proceso que algunas veces tiene lugar sin esfuerzo, y otras supone un esfuerzo consciente. Cuando nos apropiamos de un mensaje lo adaptamos a nuestras vidas y a los contextos en los que vivimos (Thompson, 1998: 66).
}

Sus "insólitas apropiaciones" serán, ciertamente, fruto de las asimetrías de un contexto que, situado "fuera de la órbita", permitirá traslucir el juego de la compresión/autocomprensión como resultado de sus mutaciones identitarias a la luz de la introducción tecnológica. En este sentido, 
destacan dos claras apropiaciones: i) hacer un uso del móvil en una situación, como antes se recogía en los relatos en primera persona, de fuera de cobertura constante o intermitente, esto es de "conexión discontinua" (de Salvador y Martínez, 2015), a la que se suman los habituales cortes de electricidad en la zona y ii) emplear un teclado, a priori, no propicio para transcribir mensajes de texto en sus propias lenguas.

Así, en primer lugar, entre las estrategias para sobrellevar el fuera de cobertura o la "cobertura intermitente" está el localizar y señalar los puntos de señal de la comunidad y acceder a ellos en las horas de conexión (por ejemplo, cuando se ha concertado una cita previa con alguien para poder hablar), para ello recurren a prácticas que se han convertido, igualmente, en algo usual.

Cuando salen a buscar lugares donde hay cobertura, todos hacen uso del celular. Ya tenemos un lugar en donde vamos a conectarnos. Ya tenemos conocido donde hay cobertura y nos vamos. En la cancha, en la escuela y siguiendo la vía a la Unión en un lado, ahí (Entrevistada kichwa 9, 45 años, San Vicente de Caney).

En esta altura, hasta el momento, no hay cobertura. Entonces, nosotros también estamos pidiendo al mismo CNT, a ver si pueden darnos esa cobertura para poder comunicarnos, desde aquí a cualquier distancia, según la provincia, los cantones, a otros más para poder contactarnos, sin estar saliendo, estar haciendo documentos, oficios. Por medio de Internet podemos hacer las llamadas escritas. Cuando no tengo la cobertura, nosotros les llamamos, ahí lo esperamos hasta que nosotros tengamos el dinerito, para salir a hacer una comisión y a dejar un buen resultado (Entrevistado shuar 4, 42 años, Yayu).

(Para buscar cobertura) lo hacemos más alto en un lugar. O a lo mejor que irnos a la mitad del río para poder comunicarnos (Entrevistado shuar 9, 26 años, Tiukcha).

Es desesperante, cuando no tienes, por ejemplo, lo que me tocó hacer aquí. Yo soy de Sucúa, de la casa de mis padres, lo que pasa es que tenía Internet desde el celular, pero ahora hay, así, cuestiones que el celular te limita ciertas opciones. Tomar una fotografía o enviar un trabajo es complicado e imposible, entonces toca confrontar un servicio de Internet. Eso porque aquí hay un medio de servicio y puedes contratar, pero en las comunidades en sí no hay una repetidora, lo que máximo podría tener es donde hay una cobertura, un Smartphone con Internet. Pero si hablamos de más alejada, donde no hay señal telefónica, esto es bastante complicado, porque tendría que acercarse a un café net que ha puesto el Gobierno, para unos cinco minutos revisar algo y poder alguien por curiosidad, porque es un cliente. Con una forma u otra tienes que buscar un medio (Entrevistado shuar 10, 33 años, Sucúa).

Suben a la loma y tienen un lugar, se pueden comunicar mediante la línea, no sé pero hay. Dicen me subo a la lomita y allí hablo con mis familiares (Entrevistada shuar 19, 46 años, Muchime).

Una zona rural hay laditos donde sí coge, por ejemplo, hay casos que dicen que en el filo de la ventana coge, otro en el segundo piso, en la terraza. Hay algunas personas que optan por colgar el teléfono y comunicarse desde allí. $O$ hay personas que viven en el sector rural e informan, sabes que en tal loma hay cobertura y en el momento de llamar se paran en una loma y llaman (Entrevistada shuar 20, 25 años, Yantzatza).

La cobertura no es muy buena, no llega mucho. Es difícil la cobertura. Tiene que buscar por ahí donde caiga más señales. (Localizan puntos) y ahí vamos para poder comunicar a donde quiera (Entrevistado shuar 26, 27 años, Wantz).

En Héroes del Cóndor no hay cobertura todavía. No tener cobertura es porque realmente nosotros estamos en algo dificultoso. No tenemos como, nosotros, poder comunicarnos cuando hay alguna necesidad. A veces hay algún accidente, y no tenemos cómo. Tenemos que bajar, quizás fletando un carrito por ahí, hasta Zurmi, más o menos. Es mucho tiempo (llegar). Ahora más o menos estamos en cómo poder comunicarnos cuando hay alguna necesidad. Hay teléfono fijo y eso ya nos permite comunicarnos. Estamos al frente del destacamento, pedimos y ya tenemos como comunicarnos. Si se quiera llamar ya se llama a celulares (...) El fijo está cerca, en el destacamento militar. Sino, venimos a Nuevo Paraíso que realmente nos facilita comunicarnos, tiene Internet (Entrevistado shuar 29, 30 años, Héroes del Cóndor).

La batería salimos por acá. Cuando nos vamos con los vecinos nos vamos a recargar. A veces tenemos generador, y se nos permite recargar (Entrevistado shuar 29, 30 años, Héroes del Cóndor). 
También recurren a la práctica de establecer una cadena de comunicadores, al salir a zonas de señal, que refuerzan su sentimiento comunitario o mejora la convivencia grupal- precisamente uno de los logros de la educación mediática implementada en contextos interculturales según las tesis de Dopico (2011). La táctica de la cadena de favores funciona como mecanismo para sobrellevar su situación de offline e incluso resignifican el uso, más extendido, del móvil como una propiedad individual. El terminal se comparte y se convierte así en objeto de préstamos para poder insertar en él los propios chips, tal y como nos comentan los protagonistas:

\begin{abstract}
Cuando los shuar van a Guayzimi, es lo que donde más acuden, entonces, piden al vecino, al papá, o a la mamá, o al hermano, y ponen su chip y con el mismo celular, cuando sale el otro igual pone su chip y el mismo celular (Entrevistada shuar 8, 27 años, Nuevo Paraíso).
\end{abstract}

(Desde Nuevo Paraíso) ahí no se puede ni cómo comunicarse. Tenemos que bajar a un sector donde haya cobertura (...) Me voy, no más, directamente yo mismo con el transporte que haiga y se podría hacer la comunicación verbalmente (Entrevistado shuar 26, 27 años, Wantz).

\begin{abstract}
Yo busco a alguien, por ejemplo si quiero comunicarme con un familiar de Loja, de Zamora o de Yantzaza, me iría abajo a las Orquídeas y de ahí llamaría. Si no, a veces va un familiar que tengo aquí, entonces le mando encargando que me de llamando, que me de comunicando (Entrevistada shuar 28, 29 años, Nuevo Paraíso).
\end{abstract}

La discriminación, en términos de cobertura, les hace apropiarse del móvil para, sin conexión, hacer usos creativos marcados por el contexto. De los mencionado por ellos, destacan sus tácticas para paliar una situación que les lleva, como hemos dicho, a reforzar los lazos con su comunidad. Bien a través del préstamo, de los encargos, o bien gracias a sistemas de intercambio de datos, como el bluetooth, comparten aquello que han conseguido descargar en zonas de cobertura.
En segundo lugar, el otro hándicap al que se enfrentan, y que les conduce a buscar e ingeniar formas alternativas de comunicarse con el móvil, es, como ya hemos dicho, el teclado; es decir, la ausencia de una interfaz en lengua indígena propia, tanto en shuar como kichwa. Tan sólo hubo un intento, llevado a cabo por la compañía telefónica Claro, de crear una interfaz que permitiese el empleo de las grafías en kichwa, pero fracasó y se retiró del mercado por la poca popularidad que alcanzó. Los entrevistados ni siquiera conocían este prototipo que se comercializó en el año 2012. Por otra parte, los indígenas consultados, fundamentalmente los shuar, explican su relación ambivalente con el teclado QWERTY que deja fuera varias de sus letras, lo que les obliga a establecer una serie de estrategias para poder garantizar la comprensil de su interlocutor/a.

Nosotros (empresa de tecnología shuar) estamos haciendo prototipos, pero son prueba, aún no se han adaptado como una interface para un equipo determinado, no se ha hecho. Todo se basa en la cuestión de recursos. Se está con la idea de querer ampliar, planificar algún desarrollo de software exclusivamente orientado para un uso, en mundo virtual, traductor virtual, hablando de Microsoft que podría ser exclusivamente en lengua shuar. Porque, hoy en día, el Gobierno está trabajando mucho en la cuestión del Buen Vivir todas las políticas, pero el material no es acorde a la realidad (Entrevistado shuar 10, 33 años, Sucúa).

Sí se tiene a veces dificultad para escribirlo, porque para mí es más fácil son 17 vocales, no utilizamos todas las letras del teclado y se le escribe un poquito más rápido incluso dos palabras definen en una sola, entonces, así es interesante. Yo he conversado mucho con mis tíos, primos, hermanos, solamente en shuar y he tenido la oportunidad de que en los dispositivos hay una manera de manejarlo fácilmente, creo que es cuestión de práctica y de ir acostumbrándonos, es un poco más fácil los dispositivos más grandes como tablets y laptops. Entonces creo que lo que se requiere aquí es, no sé, que haya una buena herramienta que pueda ayudar, unos emoticones. Rescatar la cultura que sería interesante (...) Por ejemplo, si no hay la palabra sustituta a veces se le agrega como una vocal allí para que se le pueda entender, 
entonces eso le hace más larga a la palabra (Entrevistado shuar 11, 28 años, Bambantza).

Escribimos, como digo, errando esa ortografía, pero como ya nos entendemos, que nos estamos escribiendo en nuestro idioma, lo entienden rápidamente. No tenemos mucho problema en eso (...) A veces cuando el castellano no se puede traducir palabras directamente, eso sí a veces dejamos en paréntesis o escribimos directamente en castellano, para no enredarnos mucho (Entrevistado shuar 12, 35 años, Sucúa).

En el texto lo acortan o quitan la palabra en español y se entiende. Pero en shuar a veces no es posible hacer eso. No es posible hacer eso y tienes que interpretar la palabra que quiso escribir, ya que no encuentras" (Entrevistada shuar 18, 35 años, Sucúa).

Sería importante, y yo, incluido mi hijo, él me dice mamá me admira que importante es conocer un sistema tecnológico ya más avanzado. Que no, solamente, tengas al frente una tecla que está con letras en inglés o letras que están con español. Si no tener al frente un teclado con alfabetos ya en diferentes idiomas, entonces, yo te digo, que es importante, esto no, entonces, no sé. Uno de los sueños que tenemos nosotros, y sobre todo tienen mis hijos, es que mi hijo Nanki, él quiere ser un especialista en sistemas informáticos. Entonces, él dice, por ejemplo, yo puedo hacer, me dice a mí, yo podría inventarme una computadora, donde ya no tengas textos solamente en español sino en shuar-chicham, en nuestro idioma (Entrevistada shuar 21, 43 años, Taisha).

Por teléfono sólo escribo en castellano porque ahí no me entendería el otro. Es diferente el teclado, hay letras que no entrarían. Son 16 vocales más 11. Algunas no hay en el teclado. Para hablar sí, en shuar directamente (Entrevistado shuar 26, 27 años, Wantz).

Tecnologías que los indígenas se apropian para mostrarse a sí mismos y luchar de este modo contra las heterodesignaciones. O como una ingeniero shuar, técnica de proyectos en una fundación internacional, les dice a sus compañeros indígenas:

Sería mucho mejor si ustedes pueden visibilizar su participación tan directa (...), siempre hay algo por decir, siempre hay alguien que nos está vendiendo, mostrándonos a nosotros o visibilizándonos a nosotros, cuando ustedes también lo pueden hacer (Entrevistada shuar 18, 35 años, Sucúa).
Porque pese a los hándicaps, del teclado y la interfaz, la actitud de los indígenas amazónicos entrevistados es tecno-optimista.

Es igual de fácil hablar kichwa que español por el celular, pero tengo que hablar con alguien que me entienda para poder transmitir el mensaje (Entrevistada kichwa 9, 45 años, San Vicente de Caney).

Si es que encuentra con una que sepa el kichwa, por Internet puede hablar tranquilamente, puede hablar kichwa pero si que es voy a encontrar con un amigo que no sepa kichwa, yo no puedo meter el kichwa (Entrevistado kichwa 11, 70 años, San Vicente de Caney).

En broma decía un amigo, esta computadora ha sabido escribir en shuar. Creo que los shuar tenemos esa capacidad de adaptarnos fácilmente a los cambios y hacer uso positivo de herramientas (Entrevistado shuar 2, 39 años, Sucúa).

Generalmente, yo chateo en shuar con los que son shuar (Entrevistada shuar 13, 45 años, Sevilla Don Bosco).

Yo pienso que sí es importante la tecnología, por ejemplo si ahora no se halla algún chico shuar o alguien que pueda conocer muy bien sistemas que pueda adaptar, por ejemplo, una página donde los shuar podamos, los jóvenes, sobre todo, puedan aprender a leer o a escribir shuar y que todo lo que en el Internet se pueda poner en nuestro idioma sería lo máximo que se pueda hacer. Yo estuve en México en la Universidad del Norte habían jóvenes que estaban haciendo este tipo de trabajos, me pareció importante. Entonces me interesaría que hay un joven shuar que pudiera hacer ese tipo de cosas (Entrevistada shuar 13, 45 años, Sevilla Don Bosco).

Hablo en español y en shuar. El teléfono sólo en español (Entrevistada shuar 24, 29 años, Tsarunts).

Escribir en shuar es igual de fácil que con castellano (Entrevistada shuar 24, 29 años, Tsarunts).

Hablo en shuar y redacto en shuar. Tiene todo (el teclado). Es fácil escribir en shuar, solamente es aprender nomás. Es todo fácil (Entrevistado shuar 29, 30 años, Héroes del Cóndor).

Quizás su cómoda apropiación se deba a que, como lo expresa taxativamente un entrevistado, "El pueblo shuar, a menos a nivel de Ecuador, es de los primeros pueblos indígenas que hizo 
uso de la tecnologías de la comunicación" (Entrevistado shuar 2, 39 años, Sucúa)". Opinión que va al hilo de lo expresado por la teórica de la comunicación Clemencia Rodríguez:

Cuando hablamos de apropiación de los medios, o tecnologías de información y comunicación, hay que ser cuidadoso y no olvidarse que el Sur Global, las comunidades de las cuales estamos hablando, no son quienes diseñan y desarrollan estas tecnologías. Sin embargo decir que porque las TICs se desarrollan en el norte entonces el sur está limitado a copiar al norte es una postura miope que deja de ver la multiplicidad de estrategias usadas por los pueblos del sur global para hacer que las TICs hablen el mundo y le hablen al mundo en los términos del sur. Las comunidades del sur contribuyen con tanta energía creativa como los creadores originales, energía invertida en re-diseñar, distorsionar, improvisar, hibridizar, converger, mezclar y reciclar las tecnologías que llegan del norte (Rodríguez, 2010: 2).

\section{A modo de conclusión}

Tras lo anteriormente expuesto y de acuerdo al objetivo marcado de estudiar las acepciones semánticas, se podría concluir que el concepto de modernidad trasladado a un contexto de "fuera de la órbita" -esto es a priori su contrarionos emplaza a repensar la oposición tradiciónmodernidad, así como sus categorías derivadas en la lógica racional. La construida inmovilidad del polo de la tradición/indígena se ve refutada por las voces de los protagonistas, quienes elevan a discursos sus prácticas cotidianas. Prácticas diarias que desafían ese imaginario occidental que los esencializa hasta el punto de la museificación. Si, como indicamos, las tecnologías digitales marcan las acciones e interacciones de la sociedad global actual, su apropiación por parte de un colectivo marcado, desplazado a los márgenes de la modernidad, los introduce, por obra y arte de esta acción, en el centro de los debates y las negociaciones.
Y si bien es cierto que la apropiación de las tecnologías digitales por los indígenas los moviliza a una categoría más cómoda -en tanto remite a una mayor libertad- esto es: modernidad indígena, esta situación no deja de tener sus luces y sus sombras. La apropiación por parte de un colectivo marcado implica siempre una serie de asimetrías o brechas que, como hemos reflejado a lo largo del texto, se viven de manera transnacional, en tanto las categorías que las convocan son universales y la lógica dicotómica también lo es. Pero, frente a esa desigualdad en el acceso (brechas de género, etnia, edad, zona y clase), la modernidad indígena, nos muestra una multiplicidad de usos creativos en la apropiación que los sujetos entrevistados idean para poder situarse en órbita, y dejar los márgenes de un fenómeno que los excluyó en la teoría, pero que les llegó de manera inevitable en la praxis. Usos entre los que destacan, por una parte, las adaptaciones del código para escribir los mensajes en lengua indígena en un teclado QWERTY no adecuado a éstas y, por otra parte, las cadenas de comunicadores, por proponer un término que se ajuste a las costumbres expuestas en el texto de localizar las zonas de cobertura intermitente y de prestarse los celulares cuando salen a zonas conectadas para hacer las conexiones pendientes propias y ajenas.

Desde que Wittgenstein propusiera su tesis del significado en uso, pasando por el posterior desarrollo de la pragmática, la idea de que la semántica debe dialogar con el contexto, nos emplaza a repensar conceptos desde nuevos escenarios. Así, el significado occidental de modernidad, dislocado fuera de su área de confort, nos permitió ver hasta qué punto sus acepciones mutan resituadas en nuevos contextos, lo que en última instancia evidencia 
la erosión de las categorías binarias. Categorías sobre las que pivota la modernidad vs. tradición, y de las que surgen, entre otras, la contraposición entre occidental-indígena, civilización-barbarie, online-offline, móvil-inmóvil, etc. De manera que, tomando las TIC como hilo discursivo y paradigma de una idea actual de modernidad, hemos tratado de reflexionar sobre ello emplazados en un entorno concreto, a saber: el de la Amazonía sur ecuatoriana. Si las tecnologías están asociadas a la modernidad, y los indígenas a la tradición, una reflexión en torno a las apropiaciones móviles, la versión puntera de las TIC, por parte de comunidades indígenas en contextos remotos como la Amazonía, se antoja especialmente interesante para debatir sobre tradición vs. modernidad, discusión en la que están, como hemos visto, muy presentes las brechas de primera y segunda generación, las asimetrías en la media literacy y la influencia de las variables de género, etnia y clase.

Lejos de pensar que una modernidad indígena nos ubicaría a un oxímoron semántico, por boca de sus protagonistas, a saber, de los indígenas shuar y kichwa-Saraguro, hemos podido apreciar con claridad los nuevos significados en contexto propio.

\section{Bibliografía}

Bessis, S. 2008. Los árabes, las mujeres, la libertad. Madrid: Alianza Editorial.

Bonfil, G. 1983. "Lo propio y lo ajeno: una aproximación al problema del control cultural". Revista Mexicana de Ciencias Políticas y Sociales 27: 181-191.

De Salvador, S. y Martínez, Y. 2015. "Apropiaciones comunitarias en los indígenas shuar". Revista Internacional de Comunicación y Desarrollo 1(1): 41-49.

Dopico, E. 2011. "Alfabetización intercultural con herramientas digitales". Actas del Congreso internacional de Educación Mediática y Competencia Digital. La cultura de la Participación. Segovia: Universidad de Valladolid. Disponible en: https://www.researchgate. net/publication/283573378_Alfabetizacion_Intercultural_con_ Herramientas_digitales (consultado en 16 de marzo de 2016)

García Canclini, N. 1995. Consumidores y ciudadanos: Conflictos multiculturales de la globalización. México: Grijalbo.

Martín Barbero, J. 1987. De los medios a las mediaciones. Comunicación, cultura y hegemonía. México: Gustavo Gili.

Martínez, Y., De Salvador Agra, S. y De Salvador González, X. 2015. "Triplemente marcadas: desconexiones comunicativas en la Amazonía sur ecuatoriana". Cuadernos.info. Comunicación y medios en Iberoamérica 36: 89-107. Disponible en: http://www. cuadernos.info/index.php/CDI/article/view/716/pdf (consultado en 27 de mayo de 2016)

Mernissi, F. 2005a. "Fátima Mernissi habla del fin del harén". El Periódico de Extremadura. 31/05/2005. Disponible en: http://www. elperiodicoextremadura.com/noticias/universa/fatima-mernissihabla-fin-haren_176958.html (consultado en 27 de mayo de 2016) . 2005b. El hilo de Penélope. Madrid: Lumen 2006. El Harén en Occidente. Madrid: Espasa Calpe 2007. El miedo a la modernidad. Islam y democracia. Ediciones del Oriente y del Mediterráneo.

2015. "Objetos nómadas digitales: caso de estudio las comunidades shuar ecuatorianas". Comunicaçao, midia e consumo 12 (33): 73-91. Disponible en: http://revistacmc.espm. br/index.php/revistacmc/article/view/889 (consultado en 27 de mayo de 2016)

Rodríguez, C. 2010. Tecnologías para nombrar al mundo. Procesos de apropiación y uso de las Tics. Department of Communication The University of Oklahoma

Thompson J. B. 1998. Los media y la modernidad. Una teoría de los medios de comunicación. Madrid: Paidós.

UNESCO 2013. Enfoques estratégicos sobre las TICs en educación en América Latina y el Caribe. Santiago de Chile: Organización de las Naciones Unidas para América Latina y el Caribe. 